\title{
CONTRIBUIÇÕES E DESAFIOS DO PROGRAMA DE PÓS-GRADUAÇÃO STRICTO SENSU EM ENFERMAGEM
}

Larissa Chaves Pedreira Silva - Professora Associada, Coordenadora do Programa de Pós-graduação em Enfermagem e Saúde na Escola de Enfermagem da Universidade Federal da Bahia; Vice-Líder do Núcleo de Estudos e Pesquisas do Idoso. Salvador-Bahia, Brasil. E-mail: larissa.pedreira@uol.com.br

Gilberto Tadeu Reis da Silva - Professor Titular-Livre na Universidade Federal da Bahia, Vice coordenador do Programa de Pósgraduação em Enfermagem e Saúde na Escola de Enfermagem da Universidade Federal da Bahia; Líder e Pesquisador do Grupo de Estudos e Pesquisa em Administração do Serviço de Enfermagem - GEPASE/UFBA. Bolsista de Produtividade CNPq - 2. SalvadorBahia, Brasil. E-mail: gilberto.tadeu@ufba.br

A formação de enfermeiros pesquisadores é de extrema importância para o cuidado em saúde, visando o ensino, a gestão, a pesquisa, e a extensão de qualidade, assim como as práticas gerencial e assistencial. Isso porque, a formação para a pesquisa, que pode e deve se iniciar desde a educação básica, passando pela graduação e a pós-graduação, estimula uma atitude intelectual, investigativa, reflexiva e crítica diante do mundo que se apresenta. Ademais, possibilita a aquisição e o fortalecimento de conhecimento, e a geração de tecnologias para uma prática segura, baseada em evidências, visando o bemestar da população.

Logo, o estímulo à formação de enfermeiros pesquisadores é extremamente relevante e, na graduação, a possibilidade de participação em projetos de iniciação científica e tecnológica, e em grupos de pesquisa com estudantes de mestrado e doutoramento, torna-se um elemento motivador. Nesta tônica, necessário se faz destacar que a consolidação da pós-graduação no Brasil, assim como a sua articulação com a graduação, foi também um dos fatores que determinaram o desenvolvimento da profissão.

No caso dos enfermeiros, e a guisa de trajetórias profissionais relacionadas a atividade assistencial elou gerencial, observa-se o intenso esforço para uma produção intelectual de qualidade. Assim, destacamos um dos desafios, que é a necessidade de compreensão do serviço de saúde, sobre a importância desta formação no ambiente corporativo ${ }^{(1)}$.

São poucos os serviços de saúde no Brasil que tem possibilitado que tal ação ocorra, numa perspectiva de educação permanente em serviço, ao menos no âmbito do mestrado e doutorado acadêmico. Tal situação nem sempre ocorre no Programa de Pós-Graduação Profissional, onde geralmente há uma grande articulação com o serviço.

Ademais, a atual crise no cenário da pós-graduação ${ }^{(2)}$, nos obriga a repensar a organização interna dos programas de pós-graduação, naquilo que nos é concernente, uma vez que está dado o corte nas bolsas de pesquisa a serem implementadas para estudantes de mestrado, doutoramento e pós-doutorado; 
congelamento de bolsas de produtividade em pesquisa de professores; escassez de editais nacionais de pesquisa científica; falta de recursos para o próximo ano sobretudo em edital Universal, entre outras medidas que prejudicam o andamento da Pós-Graduação de qualidade. Entendemos que o investimento na pesquisa científica é um investimento de nação, e temos exemplos internacionais exitosos como Japão, Singapura e Finlândia ${ }^{(3)}$.

O investimento em pesquisadores é a possibilidade de tornar possível a formação de quadros para a ciência e a tecnologia brasileiras, para um bem-estar da população. Logo, as bolsas estudantis objetivam permitir uma dedicação maior aos projetos de pesquisa, permitindo que os pós-graduandos tenham uma outra perspectiva de manutenção ao processo formativo. A despeito disso, os cortes impossibilitam a dedicação exclusiva do estudante ao trabalho de pesquisa e, muitas vezes, a possibilidade de sua manutenção no curso.

Frente a tantos desafios e a um futuro, por hora incerto, acreditamos na necessidade de envidar esforços em nossas estruturas instaladas, que se configuram como novos desafios: corpo docente e discente articulados com os objetivos do programa, projetos interprofissionais, busca de financiamento internacional, auto avaliação do projeto pedagógico dos cursos, busca de parcerias e fortalezas regionais, nacionais e internacionais para o financiamento, sejam instituições públicas ou privadas ${ }^{(4)}$.

É inegável os avanços que a área de Enfermagem, na área da pós-graduação cresceu em bases estruturadas, acordadas e com fortalezas para se constituir com alicerce para a profissão e dando sustentação a ciência e tecnologia ${ }^{(5)}$. O empenho em explicitar o desenvolvimento social que proporcionamos tem sido um desafio singular entre os diversos programas do país e, sobretudo, destacar a impregnação de seus impactos e contribuições efetivas para a sociedade.

A produção científica é destacada tanto na Latino-américa como no panorama global, resta-nos ainda inúmeros desafios, quiçá a constituição de redes colaborativas, consolidadas, na própria região das Américas e a busca de recursos internacionais.

Por outro lado, também, nesse movimento em prol da formação de enfermeiros pesquisadores, é imprescindível dar transparência e retorno à sociedade, das pesquisas realizadas e da sua aplicabilidade, para que esta reconheça e valorize o papel da Universidade na formação e transformação de uma sociedade ética, crítica, reflexiva e criativa em direção aos problemas a serem enfrentados.

\section{REFERÊNCIAS}

1. Scochi CGS, Munari DB, Gelbcke FL. Mestrado Profissional em Enfermagem: possibilidades frente à Política Nacional de Ciência e Tecnologia [editorial]. Revista de Pesquisa Cuidado é Fundamental. Online [periódico na internet]. 2012 [acesso 2019 Set 06];4(4). Disponível em: http://www.seer.unirio.br/index.php/ cuidadofundamental/article/view/2381/pdf_635 
2. Araújo RD (2019) O Brasil precisa avançar. E para isso, investir em ciência é cada vez mais necessário. Jornal da Ciência [publicação online]; 2019 [acesso em 7 de outubro de 2019]. Disponível em http://www.jornaldaciencia.org.br/edicoes

3. Arbix G, Salerno MS, Toledo D, Miranda Z, Alvarez R dos R. Inovação: estratégia de sete países. Brasília: Agência Brasileira de Desenvolvimento Industrial; 2010. 342 p.2016 [acesso 2019 Out 06];4(4). Disponível em: http://www.iea.usp.br/pesquisa/nucleos-de-apoio-a-pesquisa/observatorio-inovacaocompetitividade/publicacoes/online/inovacao-estrategias-de-sete-paises

4. Rodrigues RAP, Erdmann AL, Fernandes JD, AraújoTL. Pós-Graduação em Enfermagem no Brasil e no Nordeste. Revista Gaúcha de Enfermagem 2007;28(1):70-8. [acesso 2019 Set 06]. https://www.seer.ufrgs.br/RevistaGauchadeEnfermagem/article/view/4702/2620

5. Erdmann AL, Fernandes JD. Programas de pósgraduação em enfermagem no Brasil: desafios e perspectivas. Esc Anna Nery [online]. 2011 JanMar [acesso 2019 Set 06]; 15(1):7. Disponível em: http://www.scielo.br/scielo.php?script=sci_arttext\&pid=S1414-81452011000100001\&lng=pt

Como citar este artigo:

Silva, LCP, Silva, GTR. Contribuições e desafios do programa de pós-graduação stricto sensu em enfermagem. Revista de Enfermagem do Centro Oeste Mineiro. 2019;9:eEditorial. [Access ; Available in: DOI: http://dx.doi.org/10.19175/recom.v9i0.3605 